\title{
Air pollution and child respiratory diseases: the Viseu case study, Portugal
}

\author{
C. Borrego ${ }^{1}$, M. Lopes ${ }^{1}$, J. Valente ${ }^{1}$, J. Santos ${ }^{1}$, T. Nunes ${ }^{1}$, \\ H. Martins ${ }^{1}$, A. I. Miranda ${ }^{1} \&$ N. Neuparth ${ }^{2}$ \\ ${ }^{I}$ CESAM and Department of Environment and Planning, \\ University of Aveiro, Aveiro, Portugal \\ ${ }^{2}$ Faculty of Medical Sciences, New University of Lisbon, Lisbon, Portugal
}

\begin{abstract}
An urban area of inland Portugal, without severe air pollution problems as yet, was selected for this work, based on the fact that future development could lead to air quality degradation. To evaluate the influence of air pollution on 6 to 10 years old asthmatic children, environment and medical parameters were monitored. Children were selected based on the school health questionnaire validated and widely applied by the ISAAC project (International Study of Asthma and Allergies in Childhood) and submitted to medical tests at the hospital. At the same time, several field campaigns were realised to characterize the outdoor and indoor air quality of the study area in different seasons (winter and summer time). Measured parameters included meteorological data and ambient air concentrations of ozone $\left(\mathrm{O}_{3}\right)$, nitrogen oxide $(\mathrm{NO})$, nitrogen dioxide $\left(\mathrm{NO}_{2}\right)$, carbon monoxide (CO), sulphur dioxide $\left(\mathrm{SO}_{2}\right)$, benzene, toluene, ethylbenzene and xylene (BTEX), measured continuously (3 mobile labs) and using diffusive tubes (indoor and outdoor), and also particulate matter $\left(\mathrm{PM}_{10}\right.$ and $\mathrm{PM}_{2.5}$ ), using high volume and low volume samplers. Preliminary results have shown that, although the study area has no air pollution problems as yet, high levels of some pollutants, like particulate matter, could be registered, especially at night. To understand the influence of dispersion conditions on air quality, mesoscale and local scale models were applied and validated with field campaign data.
\end{abstract}

Keywords: air pollution, respiratory diseases, exposure. 


\section{Introduction}

According to the European Environment Agency [1], indoor and outdoor air pollution are the environmental factors with the greatest impact on health in Europe and are responsible for the largest burden of environment-related disease. The estimates suggest that 20 million Europeans suffer from respiratory problems every day. The evaluation made under the CAFE programme found that in the EU about 350000 people died prematurely in 2000, in particular from cardiovascular and cardiopulmonary disease, due to the outdoor air pollution caused by fine particulate matter $\left(\mathrm{PM}_{2.5}\right)$. This corresponds to an average loss of life expectancy of about 9 months for every EU citizen. According to WHO evaluation [2] air pollution was responsible for 100000 deaths and 725000 years of lost life each year in a selection of European cities within the WHO European region.

Asthma, a respiratory disease with societal costs estimated at EUR 3 billion/year, is increasing all over Europe [1]. Asthmatic persons, and particularly asthmatic children, are sensitive to air quality and several studies show a strong association between exposure to air pollution and the aggravation of asthma [3]. Childhood respiratory health/asthma is one of the four priority groups of diseases identified by the child-focused EU SCALE process and stated by the European Environment Agency as a priority on the European environment and health action plan [4].

\section{The SaudAr project}

SaudAr is the Portuguese acronym of the project "The Health and the Air we breathe", whose main objective is to contribute towards urban sustainable development by preventing air pollution problems and health related diseases in the future due to expected economical development.

This study has an interdisciplinary approach including researches from environmental and medical sciences, working together with local authorities, including the town municipality, local hospital, selected schools, industrial and trading association and an environmental research team from the local polytechnic institute.

The study encompasses four tasks: (i) case-study selection; (ii) current situation characterization, including economical, social, environmental and health aspects; (iii) future development scenarios impact assessment on air pollution and child health; (iv) development of an education and information programme. A more detailed project description is following presented.

\subsection{Task 1 - Case-study selection}

Ten Portuguese towns, located in the inland part of the country were chosen assuming that currently they do not present air pollution related problems. The town of Viseu was selected due to its strategic location, in the central Portuguese mainland region and near important road transport networks, and its projected high development in near future. This town has, simultaneously, the 
highest population density (190 inhabitants. $\left.\mathrm{km}^{-2}\right)$, the highest birth rate and the lowest mortality rate, in the group of the ten considered towns.

\subsection{Task 2 - Current situation characterization}

This task includes, besides census and statistical data, the evaluation of outdoor and indoor air quality and child health examination, performed in the course of the dedicated field campaigns.

The ISAAC (International Study of Asthma and Allergies in Childhood) questionnaire was applied to 805 children from 4 selected schools (2 located in town centre - Massorim and Marzovelos - and 2 in city suburbs - Ranhados and Jugueiros) to identify those presenting respiratory disease (sibilance). During the field campaigns these children attended the local hospital where the medical research team carried out several medical tests including respiratory function and allergy. At the same time the children's houses received an environmental technician that characterised the microbiological infestation (fungus and acarus) of microenvironments. Moreover, the air quality evaluation in the field campaigns involved also radon measurements at schools and children's houses, traffic counts in the most important roads and surface meteorological measurements. Besides the ground based information, radiosondes and tetherballoon soundings have been done.

This characterization is complemented with modelling results that provide a spatial overview of air quality levels at mesoscale and local scale, as well as urban hot-spots.

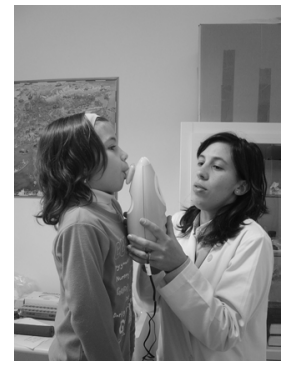

(a)

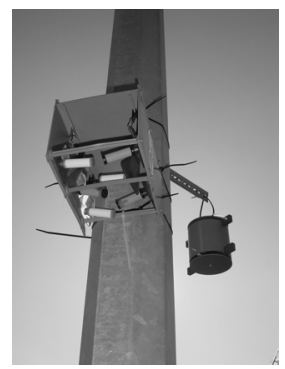

(b)

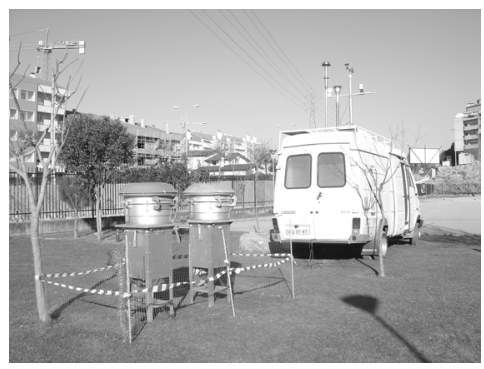

(c)

Figure 1: Child health evaluation at the local hospital (a), outdoor air pollutant measurement using passive samplers (b) and mobile air quality laboratory with high-volume PM samplers (c), during field campaigns.

\subsection{Task 3 - Future scenarios impact assessment}

Future scenarios are designed based on expected social and economic development. The municipality strategic development plan establishes the placement of different activities, changes in land use and defines the foreseen 
structural dynamics, such as road transport networks, housing or industrial parks, being an important document to be taken into account.

To build future scenarios, specific indicators are used to calculate future air pollutant emissions inventories, considering the different emission sources (industry, residential, services, traffic and other). The numerical tools will be applied to estimate air quality changes related with future scenarios; afterwards the impact on child health will be assessed with the previously established indicators.

The scenarios analysis should provide information to help the municipality to prevent pollution problems in the future and redefine the strategic plan.

\subsection{Task 4 - Development of an education and information programme}

Major attention is given to public information and education with two main objectives: (i) changing people's habits and behaviour; (ii) get people involved and participating in the decision making process. Some already carried out and foreseen activities include: the development of partnership and meetings with local authorities and interest groups, children sensitization during field campaigns, seminars, development of an internet site with a specific page for children, using simple language, animation and thematic games, and also elaboration of guidelines and booklets compiling the project main results.

\section{Indoor and outdoor air quality evaluation}

The air quality assessment in the town of Viseu was based in two experimental campaigns, one in winter (14-28 January 2006) and another in summer (19-26 June 2006). The measured parameters included ambient air concentrations of $\mathrm{O}_{3}, \mathrm{NO}, \mathrm{NO}_{2}, \mathrm{CO}, \mathrm{SO}_{2}, \mathrm{BTEX}$ (benzene, toluene, ethylbenzene, xylene), $\mathrm{PM}_{10}$ and $\mathrm{PM}_{2.5}$, measured continuously (in three mobile labs in winter and two in summer), using passive samplers and gravimetric methods, in different indoor and outdoor microenvironments. Additionally, numerical modelling simulations at mesoscale and local scale were performed.

\subsection{Air quality measurements}

\subsubsection{Particulate matter}

In the mobile laboratories installed in two schools, in urban and suburban location, $\mathrm{PM}_{10}$ concentrations were measured. In the urban school $\mathrm{PM}_{10}$ and $\mathrm{PM}_{2.5}$ concentrations where measured in the outdoor and indoor (24 hour mean) by gravimetric methods, while in the suburban school only $\mathrm{PM}_{10}$ was measured. Figure 2 presents the PM concentration values measured in the winter campaign, where it can be seen that the $\mathrm{PM}_{10}$ values measured exceeded the limit value established in the Portuguese and European legislation $\left(50 \mu \mathrm{g} . \mathrm{m}^{-3}\right)$ in some days of the experiments. The highest values were measured in the urban location.

Analysing the daily profile of $\mathrm{PM}_{10}$ concentrations it can be noticed that the peak concentrations are reached between 19:00 and 23:00. The $\mathrm{PM}_{10}$ values remain high during the night but decreasing until dawn. During daytime $\mathrm{PM}_{10}$ 
values are lower with a local maximum at 11:00. In Viseu, biomass burning for residential heating is a common practice and is a possible source for the high values registered from 19:00 to 23:00. The similar behaviour of $\mathrm{CO}$ and $\mathrm{SO}_{2}$ daily profiles, as well as the absence of these peaks in summer, reinforces this hypothesis. The measurements made in the classrooms show that the PM levels are very high. On weekdays, the $\mathrm{PM}_{10}$ concentrations in the classrooms are more than the double than in the outdoors of the same location. On weekends, the indoor PM values are similar to the ones measured in the outdoor, indicating the existence of indoor PM sources on weekdays.

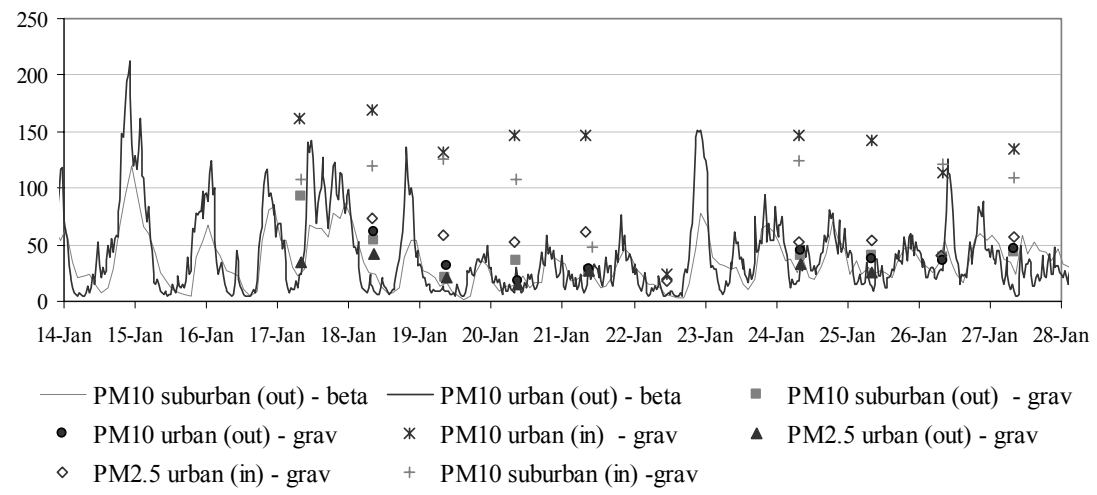

Figure 2: Particulate matter concentration values $\left(\mu \mathrm{g} . \mathrm{m}^{-3}\right)$ measured in the winter campaign. beta - beta radiation; grav - gravimetric methods.

The PM outdoor values measured in the summer campaign are lower than in the winter campaign. Even though, the 24 hour averages are quite close to the limit value, and indoor concentrations are lower and closer to the outdoor values. This fact can be explained by the higher ventilation rates promoted by opening windows, a common practice during summertime.

\subsubsection{Ozone and nitrogen oxides}

During the two campaigns, $\mathrm{O}_{3}$ and $\mathrm{NO}_{\mathrm{x}}$ concentrations were measured continuously in the mobile laboratories and using passive samplers in 20 points distributed in the town of Viseu, in an area of approximately $40 \mathrm{~km}^{2}$, and also in 44 indoor points (including children's houses and selected schools).

For the winter campaign, the $\mathrm{NO}_{x}$ and $\mathrm{O}_{3}$ values continuously measured in the mobile labs did not exceed the limit values established in the legislation. During the summer campaign, the $\mathrm{O}_{3}$ limit value for the protection of human health $\left(120 \mu \mathrm{g} \cdot \mathrm{m}^{-3}\right)$ was surpassed during three hours on the $21^{\text {st }}$ of June on the suburban measurement location. Generally, the higher $\mathrm{NO}_{\mathrm{x}}$ values were measured in the urban site, with the higher values corresponding to periods of higher traffic, while $\mathrm{O}_{3}$ measurements were higher on the suburban location.

The representation of spatial distribution of $\mathrm{NO}_{2}$ and $\mathrm{O}_{3}$ concentrations obtained by passive sampling in winter and summer periods are presented in Figure 3. 

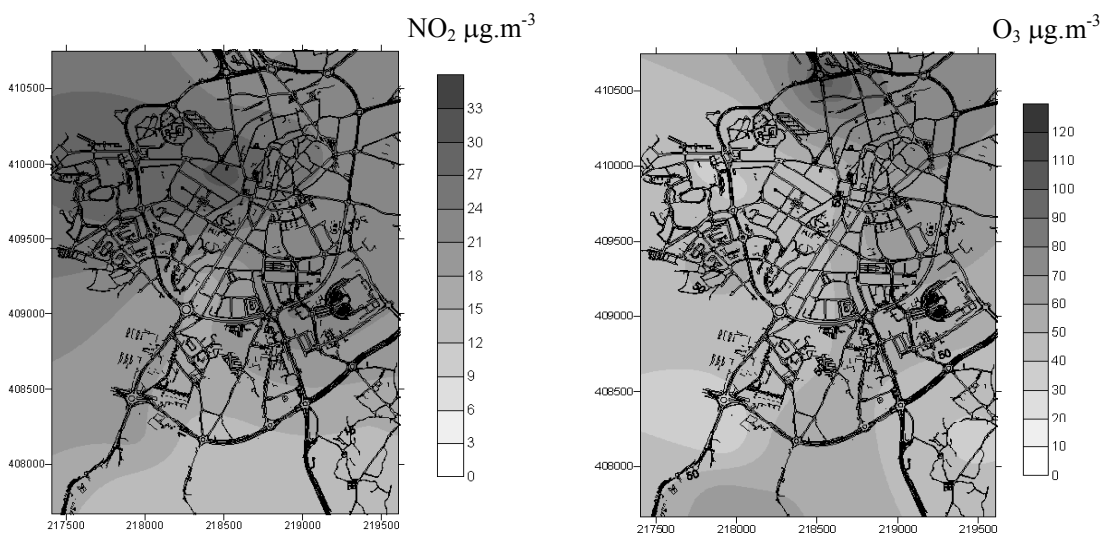

Figure 3: Spatial distribution over Viseu town, of $\mathrm{NO}_{2}$ concentrations in the winter (left) and $\mathrm{O}_{3}$ concentration in summer (right).

The results show that $\mathrm{NO}_{2}$ highest concentrations occur in areas with greater road traffic. Ozone presents a different behaviour with low values in the location of higher $\mathrm{NO}_{2}$ concentrations. Also, higher $\mathrm{NO}_{2}$ concentrations occurred in winter campaign, reaching values of $33 \mu \mathrm{g} \cdot \mathrm{m}^{-3}$, in a week basis, while the $\mathrm{O}_{3}$ remained quite low. In summer, the monitored concentrations of $\mathrm{NO}_{2}$ decreased, but the week average of $\mathrm{O}_{3}$ level increased to approximately $100 \mu \mathrm{g} . \mathrm{m}^{-3}$.

Indoor concentrations of $\mathrm{O}_{3}$ reveal ozone levels below $20 \mu \mathrm{g} \cdot \mathrm{m}^{-3}$. To evaluate the gradient of $\mathrm{NO}_{2}$ concentrations between indoor and outdoor, ten values of $\mathrm{NO}_{2}$ measured in houses were compared with nearby outdoor points, five located in the suburban area and other five situated in the urban area (Figure 4).

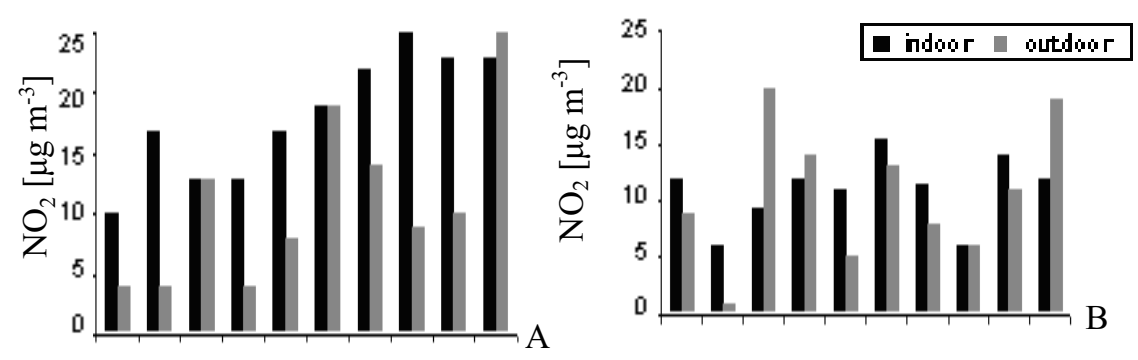

Figure 4: Relation between $\mathrm{NO}_{2}$ indoor and outdoor concentrations in winter (a) and summer (b). The first five points are located in the suburban area and the last five are located in the urban area.

In general, $\mathrm{NO}_{2}$ registered higher indoor concentrations in winter than in summer. Figure 4 shows also that the $\mathrm{NO}_{2}$ gradient concentration between indoor 
and outdoor is higher in winter; this can be explained by the presence of indoor sources, for example fireplaces are very common in this area, as well as by lower ventilation rates. Some bibliography identifies the use of domestic gas as a determinant indoor source of $\mathrm{NO}_{2}[5,6]$.

\subsubsection{BTEX and formaldehyde}

Formaldehyde and BTEX measurements were carried out for the schools (indoor and outdoor) and children's houses. The relations between indoor and outdoor concentrations of BTEX and formaldehyde were determined and are shown in Figures 5 and 6.

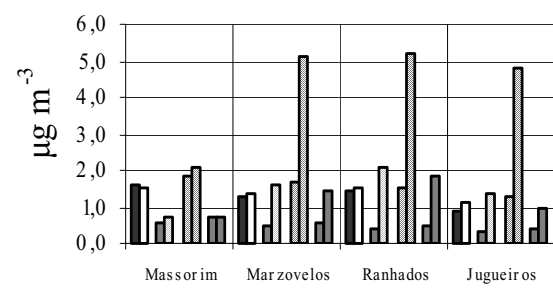

benzene outdoor

$\square \mathrm{m}+\mathrm{p}$-xylene outdoor $\square$ benzene indoor

$\square \mathrm{m}+\mathrm{p}$-xylene indoor

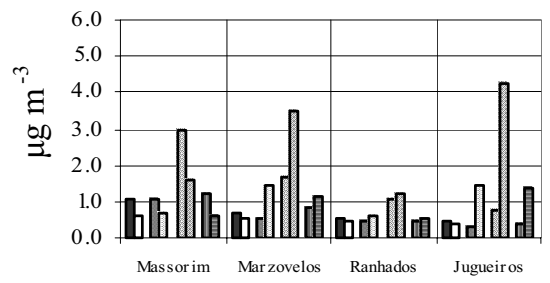

$\square$ ethylbenzene outdoor

$\square$ ethylbenzene indoor

睢o-xylene outdoor

Figure 5: Concentrations of benzene, ethylbenzene, $\mathrm{m}-/ \mathrm{p}$-xylene and $\mathrm{o}$-xylene in winter (left) and in summer (right), measured indoor and outdoor of schools.
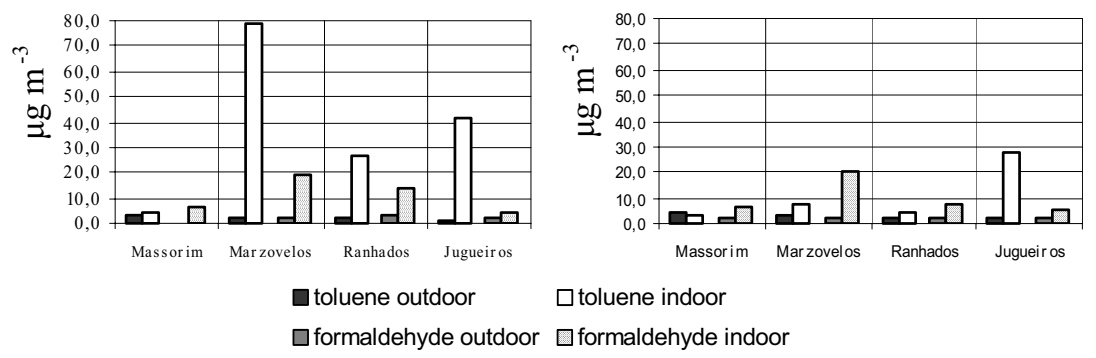

Figure 6: Concentrations of toluene and formaldehyde in winter (left) and in summer (right), measured indoor and outdoor of schools.

The concentration levels of the various organic pollutants have different behaviours. In winter indoor concentrations of toluene, formaldehyde, m-/p-/oxylene and ethylbenzene are higher than those measured outdoor; in summer this situation is similar, with exception of measurements of toluene, m-/p-/o-xylene and ethylbenzene in the school of Massorim, where outdoor concentrations are higher. This situation reveals the significance of indoor sources for these 
pollutants, such as particle board, insulation, furnishings, adhesives, solvents; in summer, the levels of measured indoor pollutants in schools appear to be lower than in winter, stressing the influence of ventilation rates in indoor air quality.

Benzene is the only organic compound which shows similar concentrations between indoor and outdoor measurements, pointing to the influence of outdoor sources in indoor air quality; also the benzene concentrations measurements were lower in summer. The threshold established for benzene $\left(5 \mu \mathrm{g} . \mathrm{m}^{-3}\right.$ in EU Directive 2000/69/CE), was never exceeded in the schools measurements.

The results obtained in the children's houses revealed that $7 \%$ of the houses had benzene concentrations higher than $5 \mu \mathrm{g} \cdot \mathrm{m}^{-3}$. The concentrations of all pollutants tend to be lower in summer, with exception of formaldehyde, which shows a concentration increase; this behaviour was already described in other studies [7].

\subsection{Air quality modelling}

Two main objectives have been considered in the simulations: the models validation for the chosen domain and the study of the regional and local air pollution dispersion patterns. Considering the mesoscale simulations, emission database was built from the national emission inventory, using a top-down approach for the spatial and temporal desaggregation. At the local scale a bottom-up approach was applied to estimate the emissions from specific sources, such as traffic.

\subsubsection{Mesoscale modelling results}

The mesoscale modelling system MM5/CAMx was applied to characterise the spatial distribution of air pollutants concentrations. The MM5 is a nonhydrostatic meteorological model, with terrain-following coordinates, which simulates and predicts atmospheric circulations at the regional scale [8]. The CAMx, is an Eulerian photochemical model that simulates the emission, dispersion, chemical reaction and removal of pollutants in the troposphere over scales ranging from urban to regional [9]. A set of four nested domains was defined: Europe (27 km horizontal resolution); Portugal (9 km resolution); Central-North Portugal (3 km resolution) and Viseu (1 km resolution). CAMx was applied to the two smaller domains.

As an example, the spatial concentration fields for $\mathrm{NO}_{2}$ obtained for the $17^{\text {th }}$ January at 9:00 PM and $\mathrm{O}_{3}$ obtained for the $20^{\text {th }}$ June, for the smallest domain, are presented in Figure 7. As expected, higher $\mathrm{NO}_{2}$ values are obtained at the city centre, while for $\mathrm{O}_{3}$, a secondary pollutant, higher levels are reached outside the city as a result of the chemical reactions and pollutants transport. As long as for $\mathrm{NO}_{2}$, the maximum concentration reached $\left(70 \mu \mathrm{g} . \mathrm{m}^{-3}\right)$ is far from the legislated limit value, $\mathrm{O}_{3}$ reaches values as high as $160 \mu \mathrm{g} \cdot \mathrm{m}^{-3}$, very close to the information threshold value $\left(180 \mu \mathrm{g} . \mathrm{m}^{-3}\right)$. Although not shown, $\mathrm{PM}_{10}$ winter simulation results reveal high levels of this pollutant, exceeding the $50 \mu \mathrm{g} \cdot \mathrm{m}^{-3}$ daily limit value. 

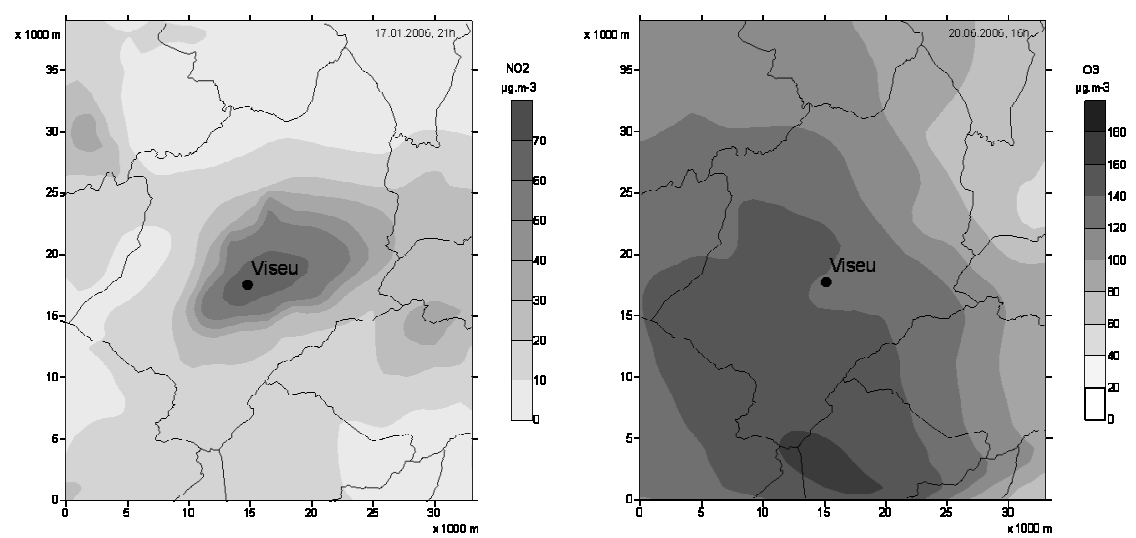

Figure 7: $\quad$ Mesoscale simulation results of $\mathrm{NO}_{2}\left(17^{\text {th }}\right.$ January 2006, 21:00) and $\mathrm{O}_{3}\left(20^{\text {th }}\right.$ June $\left.2006,16: 00\right)$ surface concentration fields.

\subsubsection{Local scale modelling results}

Preliminary simulation at local scale was performed to calculate the dispersion patterns of $\mathrm{NO}_{\mathrm{x}}$ from traffic, using the EPA Gaussian model ISCST3. The model was applied to an urban domain, with $3000 \times 2000 \mathrm{~m}$ and grid resolution of $60 \mathrm{~m}$, covering the area where the selected schools are located, and the period of $19^{\text {th }}$ to $25^{\text {th }}$ June. As input it was used the meteorological data measured in mobile laboratories during the campaign and a local station belonging to the Portuguese Meteorological Institute, and topography. Only traffic was considered, because is the most significant source of $\mathrm{NO}_{\mathrm{x}}$ in this domain, and emissions were estimated using the traffic counts done during the campaign in the streets inside the domain and selected emission factors. The modelling results show low correlation with measurements, suggesting that other sources than traffic have to be considered.

\section{Conclusions}

Concerning this air quality evaluation in Viseu, results point that, with exception for particles, the other pollutants do not attain concentration levels of major concern. Particulate matter levels in Viseu are high, particularly in winter, which can be explained by the widespread use of biomass burning for residential heating. Also, inside classrooms and on weekdays, PM levels are very high. Further experiments are being done to assess this pollutant indoor sources in schools. Both outdoor and indoor concentrations are higher in the urban measuring sites.

The results show that the highest $\mathrm{NO}_{2}$ levels are close to places with higher road traffic, while the $\mathrm{O}_{3}$ concentrations are lower in these areas. The concentrations of $\mathrm{O}_{3}$ are higher in summer than in winter, due to the higher temperatures monitored; as the ozone has its origin in photochemical reactions, has important seasonal fluctuations. From the measurements of $\mathrm{NO}_{2}, \mathrm{BTEX}$ and formaldehyde was possible to understand that indoor sources are determinant in indoor air quality. The differences found between indoor and outdoor air quality 
are due essentially to the type of activities, as well ventilation rate. The measured values were generally lower than threshold values, with exception of exceedences of benzene observed in $7 \%$ of houses.

The CAMx model presents reasonable simulation results when compared with the measured concentrations, namely identifying exceedances to the limit values. Additional work is planned for the local scale modelling, which needs to incorporate a more complete emissions inventory.

\section{Acknowledgements}

The authors are grateful to Calouste Gulbenkian Foundation for the project financial support. The authors are also grateful for the financial support under the $3^{\text {rd }}$ EU Framework Program and the Portuguese 'Ministério da Ciência, da Tecnologia e do Ensino Superior' for the Ph.D. grant of J. Valente (SFRH/BD/22687/2005) and H. Martins (SFRH/BD/13581/2003).

\section{References}

[1] EEA - European Environmental Agency. Environment and Health, EEA report No. 10/2005. Office for Official Publications of the European Communities, 2005.

[2] WHO, Health aspects of air pollution. Results from the World Health Organization project 'Systematic review of health aspects of air pollution'. WHO Europe, June 2004.

[3] F. Valent, D. Little, R. Bertollini, L. Nemer, F. Barbone, G. Tamburlini, Burden of disease attributable to selected environmental factors and injury among children and adolescents in Europe. The Lancet, Volume 363, Issue 9426, Pages 2032-2039, 2004.

[4] Commission of the European Communities, "The European Environment \& Health Action Plan 2004-2010”. COM(2004)416final, Brussels, 2004.

[5] Kousa, A., Monn, C., Rotko, T., Alm, S., Oglesby, L., Jantunen, M.J., Personal exposures to NO2 in the EXPOLIS-study: relation to residential indoor, outdoor and workplace concentrations in Basel, Helsinki and Prague. Atmospheric Environment 35 (20), 3405-3412, 2001.

[6] Lai H.K., Kendall M., Ferrier H., Lindup I., Alm S., Hänninen O., Jantunen M., Mathys P., Colvile R., Ashmore M.R., Cullinang P., Nieuwenhuijsena M.J., Personal exposures and microenvironment concentrations of PM2.5, VOC, NO2 and CO in Oxford, UK, Atmospheric Environment, Vol. 38, pp. 6399-6410, 2004.

[7] H Järnström, K Saarela, P Kalliokoski and A-L Pasanen, Reference values for indoor air pollutant concentrations in new, residential buildings in Finland, Atmospheric Environment, Volume 40, Issue 37, Pages 7178-7191, 2006.

[8] Dudhia, J. (1993). A nonhydrostatic version of the Penn State - NCAR Mesoscale Model: Validation tests and simulation of an Atlantic cyclone and cold front. Mon. Wea. Rev., 121, 1493-1513.

[9] ENVIRON (2004). Comprehensive Air Quality Model with Extensions CAMx. Version 4.0, User's guide. ENVIRON International Corporation. 